\title{
Genetic testing in asymptomatic minors
}

\section{Background considerations towards ESHG Recommendations}

\author{
Pascal Borry ${ }^{* 1}$, Gerry Evers-Kiebooms ${ }^{2}$, Martina C Cornel ${ }^{3}$, Angus Clarke ${ }^{4}$ and \\ Kris Dierickx ${ }^{1}$ on behalf of the Public and Professional Policy Committee (PPPC) of the \\ European Society of Human Genetics (ESHG)
}

\begin{abstract}
${ }^{1}$ Research Fund Flanders, Centre for Biomedical Ethics and Law, Faculty of Medicine, Katholieke Universiteit Leuven, Belgium; ${ }^{2}$ Psychosocial Genetics Unit University Hospitals, Center for Human Genetics, Katholieke Universiteit Leuven, Belgium; ${ }^{3}$ Community Genetics, Department of Clinical Genetics/EMGO Institute, VU University Medical Center, Amsterdam, The Netherlands; ${ }^{4}$ Institute of Medical Genetics, School of Medicine, Cardiff University, Heath Park, Cardiff CF14 $4 X N$, Wales, UK
\end{abstract}

Although various guidelines and position papers have discussed, in the past, the ethical aspects of genetic testing in asymptomatic minors, the European Society of Human Genetics had not earlier endorsed any set of guidelines exclusively focused on this issue. This paper has served as a background document in preparation of the development of the policy recommendations of the Public and Professional Committee of the European Society of Human Genetics. This background paper first discusses some general considerations with regard to the provision of genetic tests to minors. It discusses the concept of best interests, participation of minors in health-care decisions, parents' responsibilities to share genetic information, the role of clinical genetics and the health-care system in communication within the family. Second, it discusses, respectively, the presymptomatic and predictive genetic testing for adult-onset disorders, childhood-onset disorders and carrier testing.

European Journal of Human Genetics (2009) 17, 711-719; doi:10.1038/ejhg.2009.25; published online 11 March 2009

Although various guidelines and position papers have discussed, in the past, the ethical aspects of genetic testing in asymptomatic minors, ${ }^{1,2}$ the European Society of Human Genetics had not earlier endorsed any set of guidelines exclusively focused on this issue. This background paper was preceded by an in-depth research on the topic by Eurogentest. ${ }^{3}$ Eurogentest (http://www.eurogentest.org) aims to develop the necessary infrastructure, tools, resources, guidelines and procedures that will structure, harmonize and improve the overall quality of all the EU genetic services at the molecular, cytogenetic, biochemical and clinical level. ${ }^{4}$ Attention has also been paid to the provision of appropriate counselling related to genetic testing, the education of patients and professionals, as well as to the ethical, legal and

*Correspondence: Dr P Borry, Research Fund Flanders, Centre for Biomedical Ethics and Law, Faculty of Medicine, Katholieke Universiteit Leuven, Kapucijnenvoer 35/3, 3000 Leuven, Belgium.

E-mail: Pascal.Borry@med.kuleuven.be social issues surrounding testing. The focus of the ethics unit of Eurogentest was oriented towards the study of the ethical issues related to genetic testing in minors. This work was the starting point for this background paper, which has been prepared and supported by different types of evidence. First, research has been performed on the existing recommendations regarding predictive genetic testing in minors ${ }^{1}$ and carrier testing, ${ }^{2}$ with the intention of identifying areas of agreement and disagreement. Second, the literature on medico-ethical and medico-legal aspects of predictive genetic testing in minors, ${ }^{5}$ carrier testing, ${ }^{6,7}$ the position of minors $^{8}$ and patient rights $^{9}$ was studied. Third, a systematic literature review was performed to gather information regarding the attitudes of the different stakeholders (minors, health-care professionals, parents and relatives of the affected individuals) towards genetic testing in asymptomatic minors. ${ }^{10,11}$ Fourth, the attitudes of European clinical geneticists regarding genetic testing in asymptomatic minors were gathered. ${ }^{12-14}$ 
In 2007, contacts were made with the Public and Professional Policy Committee of the European Society of Human Genetics with the aim of developing policy recommendations on the issue. On the basis of a decision of the PPPC meeting during the ESHG conference in Nice (June 2007), an ad hoc committee, consisting of Pascal Borry (Eurogentest), Kris Dierickx (Eurogentest), Angus Clarke, Gerry Evers-Kiebooms (PPPC) and Martina Cornel (PPPC), was created. This ad hoc committee met on 15 November 2007 to discuss a first draft of a background paper and recommendations that were prepared by Pascal Borry under the supervision of Kris Dierickx. A revised version was discussed during a PPPC meeting in Amsterdam (April 2008) and Barcelona (June 2008). In order not to repeat issues that have been discussed elsewhere, reference will often be made to the abovereferenced publications.

\section{General considerations}

\section{The concept of 'best interests'}

It is a well-known rule of biomedical ethics that treatment may only be carried out after a patient has been informed of the purpose, nature, risks and consequences of the intervention, and has freely consented to it. ${ }^{15}$ When talking about health-care decisions involving children, the concept of 'best interests' takes a more central position than the concept of informed consent. Parents are responsible for their children and have the authority to make decisions on their behalf. This is not different from the context in which parents make decisions regarding genetic testing of asymptomatic minors. This responsibility includes the moral and legal right to make decisions regarding the health of their children. In most cases, as parents are those who care the most about their children and know them best, they are expected to make the best decisions for their children, guided by the standard of 'the best interest of the child' ('acting to promote the good of the individual to the maximum extent'). ${ }^{16}$ This concept is frequently used in the ethical literature ${ }^{17-21}$ and in international documents, ${ }^{22,23}$ and it has been argued that it should be a standard in health-care decisions involving children, even if the more general character of the concept often creates difficulties in interpretation when applied to concrete cases. $^{24,25}$ (eg, the distinction between benefit in terms of physical gains or in terms of social, psychological and emotional gains is often a reason for conflict). Article 3.1 of the Convention on the Rights of the Child stipulated that 'in all actions concerning children, whether undertaken by public or private social welfare institutions, courts of law, administrative authorities or legislative bodies, the best interests of the child shall be a primary consideration. $^{26}$
Participation of minors in health-care decisions

Although the 'best interest standard' is important in cases in which children cannot participate in the decisionmaking process, this standard is becoming less adequate, as children acquire more intellectual and psychosocial capacities and can take part in decisions regarding their health. Most medical-ethical literature ${ }^{27}$ on the subject emphasizes that as soon as children are able to communicate and participate in decisions that affect them, they should be encouraged to participate in all aspects of the decision-making process. They should be properly informed about the medical issues that affect them, should be able to express their views, ask questions or communicate their worries. ${ }^{28}$ It is clear that during their development, children acquire cognitive, social and emotional skills. However, intellectual capacity and emotional understanding do not necessarily develop in the same way. There is a huge individual and societal variation regarding the moment when particular levels of competence are achieved. As a consequence from an ethical perspective, a rule about competence that is solely based on age cannot be satisfactory. When assessing competence, it is important not to assess general competence, but to assess a patient's level of understanding in relation to a specific choice that has to be made. 'The nature and complexity of the decision or task, the person's ability to understand, at the time the decision is made, the nature of the decision required and its implications, are all relevant. Thus the graver the impact of the decision, the commensurately greater the competence needed to make it. ${ }^{29}$ Moreover, in the context of genetic testing, the opinion of minors should be taken into consideration, as an increasingly determining factor in proportion to his or her age and degree of maturity. All children do not develop in the same way. Children of the same age may have a different level of development or maturity. Therefore, the competence of children should be assessed on a case-by-case basis in order to take this reality into consideration. Decision-making should include, to the greatest extent possible, the assent or consent of the minor who is involved. For 'assent', we understand that healthcare professionals should help the patient achieve a developmentally appropriate awareness of the nature of his or her condition'; 'tell the patient what he or she can expect with tests and treatment(s)'; make a 'clinical assessment of the patients understanding of the situation and the factors influencing how he or she is responding (including whether there is inappropriate pressure to accept testing or therapy)'; and solicit 'an expression of the patient's willingness to accept the proposed care. ${ }^{30}$ As children develop, they should gradually become the primary guardians of personal health and the primary partners in medical decision-making. Thus, they should be able to provide consent themselves. This should include from the health-care professionals, a 'provision of information: patients should have explanations, in understandable 
language, of the nature of the ailment or condition; the nature of proposed diagnostic steps and/or treatment(s) and the probability of their success; the existence and nature of the risks involved; and the existence, potential benefits, and risks of recommended alternative treatments (including the choice of no treatment)'; the 'assessment of the patient's understanding of the above information'; the 'assessment, if only tacit, of the capacity of the patient or surrogate to make the necessary decision(s)'; and the 'assurance, insofar as is possible, that the patient has the freedom to choose among the medical alternatives without coercion or manipulation. $^{30}$

The European legislation with regard to the legal position of minors related to interventions in the health field is different in the various European nations. ${ }^{8}$ However, at the European level, the European Convention on Human Rights and Biomedicine of the Council of Europe ${ }^{31}$ contains a specific provision - Article 6 - related to the protection of persons who are unable to consent. Paragraph 2 of this article, furthermore, stipulates: 'Where, according to law, a minor does not have the capacity to consent to an intervention, the intervention may only be carried out with the authorisation of his or her representative or an authority or a person or body provided for by law. The opinion of the minor shall be taken into consideration as an increasingly determining factor in proportion to his or her age and degree of maturity.' In view of the preservation of the autonomy of persons with regard to interventions affecting their health, the Explanatory Report, furthermore, states that in certain situations which take account of the nature and seriousness of the intervention as well as the minor's age and ability to understand, the minor's opinion should increasingly carry more weight in the final decision'. According to the Explanatory Report in some cases, it could therefore even be concluded that, the consent of a minor should be necessary, or at least sufficient for some interventions. In this respect, a reference is made to Article 12 of the United Nations Convention on the Rights of the Child, which stipulates that 'States Parties shall assure the child, who is capable of forming his or her own views the right to express those views freely in all matters affecting the child, the views of the child being given due weight in accordance with the age and maturity of the child'. Therefore, in the context of genetic tests that can easily be postponed until the minor can participate in the decision-making process, this should be carried out as much as possible in order to enable the minor to realize his decision-making capacities.

\section{Parents' responsibility to share genetic information: prerequisites and difficulties}

The communication of genetic information is often a difficult issue. It has been reported that the desire not to cause anxiety or alarm, geographical distances, family conflicts, relational ruptures, adoption, generational gaps or complex family relations have been reported as issues that might make it more difficult to convey information to relatives or children. ${ }^{32}$ Moreover, the decision not to provide relevant genetic information to relatives might be based on, the one hand, a the deliberate choice of a person not to disclose results ${ }^{33}$ or, on the other hand, the inability to communicate genetic risk information. In addition, several empirical studies have shown that adults may encounter difficulties in understanding and assessing genetic risk, ${ }^{34,35}$ as well as in understanding the recessive patterns of inheritance. ${ }^{36,37}$ Several studies $^{38-40}$ have reported that parents may experience difficulties in the retention of test results, and other studies ${ }^{39,41-44}$ have observed a low recall of residual risk after a negative test in the long term in spite of post-test counselling. Although a majority of the studies understand the concept and relevance of carrier status, almost all studies report that some individuals experience difficulties in understanding carrier status. Furthermore, different studies ${ }^{45}$ observed that some parents continue to have difficulties regarding information about the carrier status of their children. ${ }^{36,46}$ Mischler et $a l^{47}$ reported that a few families did not understand the meaning of being a carrier, and seemed to believe that their carrier children might develop cystic fibrosis. Another study found that 1 year after the carrier detection, through neonatal screening, $15 \%$ of the families were not sure whether carrier status implied health difficulties. ${ }^{48}$ It is more than likely that these parents will not be able to transmit accurate information to their offspring regarding their genetic risk. Children in these families might make the same erroneous assumptions and believe that they are or will become sick. Parents might initiate a socialization of the child into a sick role. ${ }^{36}$ Some evidence suggests that although parents are the best placed to inform their children of their genetic risk, some of them decline to tell their children or family members, ${ }^{49-53}$ defer disclosure of genetic risk, ${ }^{49}$ encounter difficulties in telling their children or family members ${ }^{54,55}$ or share the information in a way that results in many family members not being fully aware of their risk of being a carrier. ${ }^{37}$ Therefore, parents have an important obligation to make a reasonable effort to understand the nature and implications of genetic information, to provide appropriate information to their children and to share their concerns and needs. ${ }^{56}$ They may assist their children in contacting genetic services later for further information and genetic counselling. In general, clinical genetic services and the health-care system may have an important role in this communication process. Although genetic services are not currently set up to recontact individuals regarding genetic test results at a later age, ${ }^{57}$ they have a responsibility towards supporting parents in the communication of genetic risk information to their children. 
The role of clinical genetics and the health-care system in the communication within the family

The role of genetic counselling in genetic services is mainly to support, insofar as possible, decisions regarding genetic testing. It has been emphasized that the goal of genetic counselling is to provide accurate, full and unbiased information to individuals and families. Non-directive counselling does not mean just presenting information and letting people make their own decisions without any help or support. The counselling sessions should be oriented to empower individuals and families to make their own decisions. It should guide and help people to work towards their own decisions, a priori with regard to reproductive decisions, and if adequate preventative interventions or therapies are not immediately available. It is linked to the original intent of genetic counselling to respect the profoundly personal nature of decisionmaking. ${ }^{58}$ It is clear that the counsellor is not completely unbiased, but he should be aware of his personal values and should not attempt to impose them on individuals or families. ${ }^{59,60}$ However, genetic counsellors and clinical geneticists cannot be obliged to perform actions that are opposed to good clinical practice. On the one hand, they can refuse actions that are not in the best interests of a child (eg, childhood genetic testing for adult-onset disorders, see below). On the other hand, if parents refuse genetic testing and eventually therapeutic actions or preventive measures aimed at therapeutic interventions that might be life saving for a child, health professionals have the responsibility to use all means for promoting the benefit of the child. Preliminary results of a recent research ${ }^{61}$ showed that parents and children often felt that minors were not engaged sufficiently in the decisionmaking process by suitably trained professionals. Parents and children often felt their needs as a family were not considered, not only in relation to genetic testing but also in dealing and coping with the outcomes. Parents were often present during consultation about a minor, and parents and children were aware that parental anxieties and concerns were more focused on by the health-care professional than the child's. This suggests that there is probably a need for developing skills and expertise of specialist health-care professionals in working specifically with young people about making these decisions.

\section{Presymptomatic and predictive genetic testing}

Presymptomatic and predictive genetic testing makes it possible to provide information regarding future health risks in asymptomatic persons. As presymptomatic or predictive genetic testing may have far-reaching consequences for test applicants, their family members and society, ${ }^{62}$ concerns have always been raised about the pre-test and post-test counselling process, the provision of adequate information, the private and confidential character of the test result, the psychosocial impact of a test $^{63}$ and the responsibility towards blood relatives. ${ }^{64-66}$ An even more cautious approach has been envisaged when considering such testing in children and adolescents. This originates from the fear that testing in childhood or adolescence could create devastating social, emotional, psychosocial and educational consequences in the child or in the adolescent. ${ }^{67-69}$

\section{Presymptomatic and predictive genetic testing for adult-onset disorders}

In the past, presymptomatic and predictive genetic testing in minors has been the subject of up to 27 guidelines and position papers. ${ }^{1}$ Despite the extensive number of guidelines published and the variety of guideline developers, a great unanimity has been observed with regard to the issue of predictive genetic testing for adult-onset disorders. They all clearly suggested that, when talking specifically about predictive and presymptomatic tests for late-onset disorders, such testing is only recommended when 'established, effective, and important medical treatment' ${ }^{2,70} \mathrm{can}$ be offered or when testing 'provides scope for treatment which to any essential degree prevents, defers or alleviates the onset of disease or the consequences of the development of the disease. ${ }^{71}$ In a similar way, they emphasize that presymptomatic and predictive genetic testing should be delayed until adulthood, except for disorders for which preventive actions (preventive surgery or early detection strategies aimed at therapeutic interventions) could be initiated before that time. A similar attitude was reported in a recent survey of European clinical geneticists. ${ }^{14}$

Considering that minors do not have any prospect of effective treatment to benefit from in this case, it has been questioned whether non-medical benefits might provide convincing arguments in favour of predictive genetic testing in minors with adult-onset disorders. ${ }^{72}$ First, it has been argued $^{73}$ that persons who undergo genetic testing and receive 'good news' may learn definitively, or with a high probability, that they will not develop the disease and that those individuals who have inherited the mutation are able to anticipate the future and plan their lives. However, various concerns have been raised. It has been reported that receiving good news may also lead to psychological and social distress and troubling family relations. ${ }^{74}$ A study also showed that receiving such DNA results did not always reassure the parents about the health situation of their children. ${ }^{75}$ Even receiving favourable news and reassurance might affect people's self-image and the family dynamics. ${ }^{76}$ Second, it has been argued ${ }^{77}$ that by testing early in life, this 'information becomes part of personal identity. When a child learns personal genetic information early in life, it can be absorbed and accommodated into their identity. When the information is disclosed later in life, it can conflict with their self-image and be very hard to internalize and accept. ${ }^{78}$ Studies have indeed shown that 
'it is easier for a young person to deal with the news of risk than it would be at an older age ${ }^{79}$ However, it has been emphasized that there is a difference between being told to be at risk for a disease that exists within a family on the one hand, and performing a genetic test for an adult-onset disorder on the other. ${ }^{72}$ Third, various studies ${ }^{80-82}$ have shown that parents might believe that detection in childhood might help prepare their children and themselves psychologically for the future. Various parents who have been tested for a specific disease and who know that their children are at risk, might argue that the uncertainty of not knowing is more burdensome than receiving a negative or positive test result. Therefore, some parents consider that they should be able to consent to genetic testing in their children for diseases that only have their onset in adulthood. However, the risk to relatives, the absence of an effective cure, the potential loss of health insurance, the financial costs of testing and the inability to 'undo' the knowledge have been identified as reasons why adults decide not to undergo predictive genetic tests for adultonset disorders. ${ }^{76}$ Considering that minors, far more than their parents, will be living with the repercussions of the test results, there are good reasons that they should be able to decide about the participation in such a genetic test. ${ }^{83}$ The presence of severe anxieties and uncertainties in parents about a potential genetic mutation might be an indication for further psychological support in order to address these emotions rather than a clear indication for testing.

Presymptomatic and predictive genetic testing for preventable or treatable childhood-onset disorders In an earlier study, ${ }^{1}$ it has been reported that professional guidelines and position papers recommended that the presence of medical benefit should be the primary justification of genetic testing in children and adolescents. Therefore, from an ethical point of view, in the case of preventable or treatable childhood-onset disorders, the most crucial question is not whether the test should be done, but when it should be done. In this context, various other guidelines have referred to the fact that testing should be recommended when the results are of 'immediate' relevance ${ }^{84,85}$ for their health or may offer 'timely' ${ }^{86-89}$ medical benefit.

\section{Presymptomatic and predictive genetic testing for unpreventable or untreatable childhood-onset disorders}

Various positions have been advanced regarding the issue of predictive genetic testing for unpreventable or untreatable childhood-onset disorders. ${ }^{1}$ On the basis of a medical benefit argumentation, some ${ }^{66,70}$ have argued that the absence of measures to prevent the disease or its complications or to treat the disease is a reason not to perform this test. Although still acknowledging the importance of medical benefit as a justification for predictive genetic testing, it has been recognized that there are circumstances in which not testing might create more harm than testing. ${ }^{89-93}$ Therefore, it has been advanced that 'parents should have discretion to decide about genetic testing for childhood diseases that are unpreventable and untreatable.' 89 'Since, with unpreventable and untreatable genetic diseases, there are both benefits and risks to genetic testing, and neither the benefits or risks clearly outweigh the other, parents generally should be allowed to decide about testing for their children. ${ }^{\prime 89}$ For these guidelines, testing is considered appropriate on condition that 'testing would be in the child's best interests' ${ }^{89}$ As best interests cannot be understood in this context as a medical benefit, it should be understood here as a psychological or social benefit.

\section{Carrier testing}

Borry et $a l^{2}$ reported that professional recommendations were in agreement that carrier testing of minors in families affected by autosomal recessive or X-linked disorders or by balanced chromosomal rearrangements, ideally should be deferred. As carrier testing has the potential of affecting the future reproductive prospects of a child, the studied guidelines emphasized that the decision to test should be made by the child when he reaches the age of maturity. This view is based on the basic ethical principle of informed consent, by which an individual can freely and voluntarily give, without external pressure, his consent to be tested after being informed of the benefits, risks, procedures and other pertinent information relating to the carrier test. As carrier testing performed during childhood only affects the future of that child, not that of his parents or guardians, the guidelines stated that it is wiser to defer testing until the child himself is able to give proper informed consent, than to acquiesce to the wishes of his parents or guardians to go forward with testing. The child's personal consent takes precedence over the wishes of third parties, including parents, either to carry out or to refuse genetic testing. Knowledge of carrier status critically impacts future decisions regarding reproduction (eg, carrier testing of partner, prenatal diagnosis, artificial insemination, pre-implantation genetic diagnosis, adoption, not to have children). Some guidelines suggested that carrier testing performed during childhood also denies the child of confidentiality, a right he would expect if tested as an adult. The majority of European clinical geneticists also supports this position. ${ }^{12}$ This stance holds for autosomal recessive disorders, in which the risk for offspring would generally be $<1 \%$, and also for the X-linked disorders and balanced chromosomal rearrangements carrier, in which risks for the offspring can be much higher $(25 \%$ for $\mathrm{X}$-linked disorders, for instance). 
However, various studies ${ }^{11}$ have shown that an important group of parents are in favour of carrier testing in their children before the age of legal majority and some parents are even in favour of testing in early childhood. ${ }^{94}$ Arguments in favour of carrier testing on parental request concentrate on the issues that learning one's carrier status while young may help their children adapt to the carrier status, reduce the uncertainty about the carrier status, avoid resentment from children later in life and may be in accordance with the conviction that parents have the right and the ability to make decisions regarding their children's health. ${ }^{95}$ An important parental concern is that their children become aware of their genetic risk before becoming sexually active and that their child is able to chose a partner, informed of his carrier status. Some parents consider that a good parent should know as much as possible about their children, and that it is to the emotional benefit of the child to grow up knowing his or her carrier status before becoming sexually active. $^{96}$

A recent development that challenges the governing professional recommendation is that DNA testing becomes more and more integrated in newborn screening programmes. This recent development offers ethical challenges that were not present in the context of the traditionally used biochemical testing methods for detecting inherited disorders. The use of DNA mutation analysis might, in addition to identifying affected infants, also inadvertently identify mutation carriers who will be unaffected, but at risk of having children with the disorder for which they underwent the screening. In the past, various newborn screening programmes often did not report the identification of the detected carriers. ${ }^{97}$ Moreover, professional guidelines from the American Medical Association and the German Society of Human Genetics recommended that this information should not be disclosed to parents or to third parties. Rather, they recommended that this information should be discussed with the child when he or she reaches reproductive age. The guidelines from the American Medical Association provided instructions for maintaining the confidentiality of this genetic information, stating that this privileged information should be kept in a separate portion of a patient's medical record to prevent accidental disclosure. However, no clear instructions are offered as to at what age and by whom this information should be given. However, new screening programmes ${ }^{98,99}$ seem to orient practice more and more into the direction that parents should be told about this possibility before the test, and that results should be given to the parents together with adequate counselling by a health-care professional. This is in line with recommendations offered by the British Medical Association and by the American Academy of Pediatrics, who had earlier already defended the concept that carrier status results obtained incidentally (eg, after screening or prenatal diagnosis) should be conveyed to the parents. Therefore, it was reported that rigid and diametrically opposed recommendations regarding the disclosure of carrier status in two different settings (ie, clinical setting and screening context) is conflicting, and should be harmonized. ${ }^{7}$ Incidental discovery of carrier status in a parent may occur when investigating whether a possible pathogenic finding in a child is a de novo occurrence, when using array-based genome investigations for CNVs. An accidental discovery that a woman has a deletion affecting, eg, DMD or BRCA1 might occur. At present, it may not possible to counsel all parents about this possibility beforehand. With the increasing use of high-throughput technology and the decreasing prices of genomic information, the problem of incidental findings needs to be discussed urgently. For practical purposes, and before consensus is reached on the reporting of incidental findings, it may be advisable to ignore data that are not relevant for the pathology in the patient.

\section{Conclusions}

Recent developments in genetics have created expanding possibilities for genetic testing. Similar to many other fields of human activity, larger choice means a larger responsibility. Genetic testing offers the possibility to know the individual risk for a genetic disorder. When adult relatives of an affected individual are at risk for a disorder, they can decide for themselves whether to undergo a genetic test. In this background paper, we described that those health-care decisions that affect minors should be considered with special caution. A great unanimity has been reported in situations, in which predictive genetic testing might lead to an established and effective medical treatment or provides the possibility of preventive actions that can be initiated before the onset of the disorder. As soon as minors, in proportion to their age and degree of maturity, are able to participate in the decision-making, their opinion should be taken increasingly into consideration. In respect of national legislation, minors should be able to decide personally regarding a genetic test when they are well informed, have an adequate understanding of the test and its potential consequences, have the capacity to make this decision, are not exposed to external pressure and have had appropriate counselling. This background paper concisely reviews the major discussions with regard to predictive genetic testing for adult-onset disorders, preventable or treatable childhood-onset disorders, unpreventable or untreatable childhood-onset disorders and carrier testing.

\section{Acknowledgements}

Part of this contribution was supported by the Eurogentest Network of Excellence of the EU, FP6-512148. 
Members of the PPPC in 2007-2008 were:

Martina Cornel, chair, MD, Epidemiologist, Professor of Community Genetics and Public Health Genomics, Department of Clinical Genetics/EMGO Institute, VU University Medical Center, Amsterdam, The Netherlands; Gerry Evers-Kiebooms PhD, Psychologist, Psychosocial Genetics Unit University Hospitals, Katholieke Universiteit Leuven, Belgium; Ségolène Aymé MD, Medical Geneticist and Epidemiologist, Project Leader of ORPHANET, INSERM, Paris, France; Suzanne Braga MD, Medical Geneticist, Psychotherapist, Family therapist and counselor, SGMG/SSGM, Bern, Switzerland; Franca Dagna Bricarelli Professor, Human Genetics Laboratory, Galliera Hospital, Genoa, Italy; Shirley Hodgson Professor of Cancer Genetics, Honorary Consultant in Clinical Genetics, Department of Clinical Genetics, St George's Hospital, University of London, London, UK; Gyorgy Kosztolany Professor, Director of the Department of Medical Genetics, University of Pécs, Hungary; Jan Lubinski, MD, PhD, Professor, Department of Genetics and Pathology, International Hereditary Cancer Center, Pomeranian Medical University, Szczecin, Poland; Meral Özgüc, Professor, Department of Medical Biology, Faculty of Medicine, Hacettepe University Ankara, Turkey; Christine Patch PhD, RN, Consultant Genetic Counsellor and Manager, Guys and St Thomas' NHS Foundation Trust, London, UK; Jorge Sequeiros MD, Professor in Medical Genetics, Head of the Department of Human Genetics, University of Porto, Porto, Portugal; Lisbeth Tranebjaerg MD, PhD, Professor in Genetic Audiology, Department of Audiology, H:S Bispebjerg Hospital and Wilhelm Johannsen Centre of Functional Genomics, University of Copenhagen, Denmark; Veronica van Heyningen Dphil, FRS, FRSE, FMedSci, Honorary Professor of Edinburgh University, MRC Human Genetics Unit, Western General Hospital, Edinburgh, UK

\section{References}

1 Borry P, Stultiens L, Nys H, Cassiman JJ, Dierickx K: Presymptomatic and predictive genetic testing in minors: a systematic review of guidelines and position papers. Clin Genet 2006; 70: $374-381$.

2 Borry P, Schotsmans P, Fryns JP, Dierickx K: Carrier testing in minors: a systematic review of guidelines and positions statements. Eur J Hum Genet 2006; 14: 133-138.

3 Hayhurst R, Cassiman JJ: EuroGentest standing up to scrutiny first year demonstrates good progress harmonizing community approaches. J Appl Genet 2006; 47: 5-7.

4 Cassiman JJ: EuroGentest - a European Network of Excellence aimed at harmonizing genetic testing services. Eur J Hum Genet 2005; 13: 1103-1105.

5 Borry P, Fryns JP, Dierickx K: Predictive genetic testing in children. A clinical-ethical analysis; in de Bouvet A, Boitte P, Aiguier G (eds): Questions éthique en médicine predictive. Montrouge, Editions John Libbey Eurotext, 2006, pp 89-98.

6 Borry P, Dierickx K: Carrier testing for congenital adenal hyperplasia: ethical issues. Cares 2007; 6: 16-18.

7 Borry P, Nys H, Dierickx K: Ethics watch - carrier testing in minors: conflicting views. Nat Rev Genet 2007; 8: 828 .

8 Stultiens L, Goffin T, Borry P, Dierickx K, Nys H: Minors and informed consent: a comparative approach. Eur J Health Law 2007; 14: 21-46.

9 Nys H, Stultiens L, Borry P, Goffin T, Dierickx K: Patient rights in $\mathrm{EU}$ member states after the ratification of the convention on human rights and biomedicine. Health Policy 2007; 83: 223-235.

10 Borry P, Stultiens L, Nys H, Dierickx K: Attitudes towards predictive genetic testing in minors for familial breast cancer: a systematic review. Crit Rev Oncol Hematol 2007; 64: 173-181.
11 Borry P, Schotsmans P, Fryns JP, Dierickx K: Attitudes of minors, parents and health professionals towards carrier testing in minors: a systematic review. Genet Couns 2005; 16: $341-352$.

12 Borry P, Goffin T, Nys H, Dierickx K: Attitudes regarding carrier testing in incompetent children. A survey of European clinical geneticists. Eur J Hum Genet 2007; 15: 1211-1217.

13 Borry P: Minors and informed consent in carrier testing. A survey of European clinical geneticists. J Med Ethics 2008; 34: 370-374.

14 Borry P, Goffin T, Nys H, Dierickx K: Attitudes regarding predictive genetic testing in minors. A survey of European clinical geneticists. Am J Med Genet C Semin Med Genet 2008; 148C: $78-83$.

15 Andorno R: The Oviedo Convention: a European framework at the intersection of human rights and health law. J Int Biotechnol Law 2005; 2: 133-143.

16 Buchanan AE, Brock DW: Deciding for Others. Cambridge: University Press, 1989

17 Dawson A: The determination of the best interests in relation to childhood immunisation. Bioethics 2005; 19: 72-89.

18 Downie RS, Randall F: Parenting and the best interests of minors. J Med Philos 1997; 22: 219-231.

19 Ross LF: Health care decision making by children. Is it in their best interest? Hastings Cent Rep 1997; 27: 41-45.

20 Spence K: The best interest principle as a standard for decision making in the care of neonates. J Adv Nurs 2000; 31: 1286-1292.

21 Trau JM, McCartney JJ: In the best interest of the patient. Applying this standard to healthcare decision making must be done in a community context. Health Prog 1993; 74: 50-56.

22 Charter of Fundamental Rights of the European Union, http:// www.europarl.europa.eu/charter/pdf/text_en.pdf, 2000.

23 Universal Declaration on the Human Genome and Human Rights; Unesco, http://portal.unesco.org/shs/en/ev.php-URL_ID $=1881 \&$ URL_DO = DO_TOPIC\&URL_SECTION $=201 . h t m l, 1997$.

24 Kopelman LM: The best-interests standard as threshold, ideal, and standard of reasonableness. I Med Philos 1997; 22: 271-289.

25 Kopelman LM: Children and bioethics: uses and abuses of the best-interests standard. J Med Philos 1997; 22: 213-217.

26 United Nations. Convention on the Rights of the Child, http:// www.unhchr.ch/html/menu3/b/k2crc.htm, 1989.

27 Alderson P, Montgomery J: Health Care Choices: Making Decisions with Children. London: Institute for Public Policy Research, 1996.

28 Royal College of Psychiatrists Report: Appendix 2 - Children's Level of Understanding of Medical Decisions; Guidance for Researchers and for Ethics Committees on Psychiatric Research Involving Human Participants. London: The Royal College of Psychiatrists, 2001.

29 British Medical Association: Consent, Rights and Choices in Health Care for Children and Young People. London: BMJ Books, 2001.

30 Informed consent, parental permission, and assent in pediatric practice: Committee on Bioethics, American Academy of Pediatrics. Pediatrics 1995; 95: 314-317.

31 Council of Europe. Convention for the Protection of Human Rights and Dignity of the Human Being with regard to the application of Biology and Medicine: Convention on Human Rights and Biomedicine. Oviedo, Council of Europe, 1997.

32 Clarke A, Richards M, Kerzin-Storrar L et al: Genetic professionals; reports of nondisclosure of genetic risk information within families. Eur J Hum Genet 2005; 13: 556-562.

33 Loud JT, Weissman NE, Peters JA et al: Deliberate deceit of family members: a challenge to providers of clinical genetics services. J Clin Oncol 2006; 24: 1643-1646.

34 Fanos JH: Developmental tasks of childhood and adolescence: implications for genetic testing. Am J Med Genet 1997; 71 (1): $22-28$.

35 Denayer L, Welkenhuysen M, Evers-Kiebooms G, Cassiman JJ, Van den BH: Risk perception after CF carrier testing and impact of the test result on reproductive decision making. Am J Med Genet 1997; 69: 422-428.

36 Fanos JH, Johnson JP: Perception of carrier status by cystic fibrosis siblings. Am J Hum Genet 1995; 57: 431-438. 
37 Denayer L, De Boeck K, Evers-Kiebooms G, Van den BH: The transfer of information about genetic transmission to brothers and sisters of parents with a CF-child. Birth Defects Orig Artic Ser 1992; 28: 149-158.

38 Axworthy D, Brock DJ, Bobrow M, Marteau TM: Psychological impact of population-based carrier testing for cystic fibrosis: 3-year follow-up. UK Cystic Fibrosis Follow-Up Study Group. Lancet 1996; 347: 1443-1446.

39 Bekker H, Modell M, Denniss G et al: Uptake of cystic fibrosis testing in primary care: supply push or demand pull? BMJ 1993; 306: $1584-1586$.

40 Bekker H, Denniss G, Modell M, Bobrow M, Marteau T: The impact of population based screening for carriers of cystic fibrosis. J Med Genet 1994; 31: 364-368.

41 Watson EK, Mayall E, Chapple J et al: Screening for carriers of cystic fibrosis through primary health care services. BMJ 1991; 303: $504-507$

42 Mennie ME, Gilfillan A, Compton M et al: Prenatal screening for cystic fibrosis. Lancet 1992; 340: 214-216.

43 Callanan NP, Cheuvront BJ, Sorenson JR: CF carrier testing in a high risk population: anxiety, risk perceptions, and reproductive plans of carrier by 'non-carrier' couples. Genet Med 1999; 1: 323-327.

44 Marteau TM, Michie S, Miedzybrodzka ZH, Allanson A: Incorrect recall of residual risk three years after carrier screening for cystic fibrosis: a comparison of two-step and couple screening. Am J Obstet Gynecol 1999; 181: 165-169.

45 Fanos JH, Mackintosh MA: Never again joy without sorrow: the effect on parents of a child with ataxia-telangiectasia. Am J Med Genet 1999; 87: 413-419.

46 Fanos JH, Nickerson BG: Long-term effects of sibling death during adolescence. J Adolesc Res 1991; 6: 70-82.

47 Mischler EH, Wilfond BS, Fost $\mathrm{N}$ et al: Cystic fibrosis newborn screening: impact on reproductive behavior and implications for genetic counseling. Pediatrics 1998; 102: 44-52.

48 Ciske DJ, Haavisto A, Laxova A, Rock LZ, Farrell PM: Genetic counseling and neonatal screening for cystic fibrosis: an assessment of the communication process. Pediatrics 2001; 107: $699-705$.

49 Forrest K, Simpson SA, Wilson BJ et al: To tell or not to tell: barriers and facilitators in family communication about genetic risk. Clin Genet 2003; 64: 317-326.

50 Varekamp I, Suurmeijer TP, Brocker-Vriends $\mathrm{AH}$ et al: Carrier testing and prenatal diagnosis for hemophilia: experiences and attitudes of 549 potential and obligate carriers. Am J Med Genet 1990; 37: 147-154.

51 Varekamp I, Suurmeijer T, Brocker-Vriends A, Rosendaal FR: Hemophilia and the use of genetic counseling and carrier testing within family networks. Birth Defects Orig Artic Ser 1992; 28: $139-148$.

52 Varekamp I, Suurmeijer TP, Rosendaal FR, Brocker-Vriends AH: The use of preventive health care services: carrier testing for the genetic disorder haemophilia. Soc Sci Med 1993; 37: $639-648$

53 Sorenson JR, Jennings-Grant T, Newman J: Communication about carrier testing within hemophilia A families. Am J Med Genet 2003; 119C: 3-10.

54 Fanos JH, Johnson JP: Barriers to carrier testing for adult cystic fibrosis sibs: the importance of not knowing. Am J Med Genet 1995; 59: 85-91.

55 Duster T: The social consequences of genetic disclosure; in: Carson RA, Rothstein MA (eds): Behavioral Genetics. The Clash of Culture and Biology. London: John Hopkins University Press, 1999, pp $172-188$.

56 Sharpe NF: The duty to recontact: benefit and harm. Am J Hum Genet 1999; 65: 1201-1204.

57 Borry P, Dierickx K: What are the limits of the duty of care? The case of clinical genetics. Per Med 2008; 5: 101-104.

58 Biesecker BB: Future directions in genetic counseling: practical and ethical considerations. Kennedy Inst Ethics J 1998; 8: 145-160.
59 Elwyn G, Gray J, Clarke A: Shared decision making and non-directiveness in genetic counselling. J Med Genet 2000; 37: $135-138$.

60 Oduncu FS: The role of non-directiveness in genetic counseling. Med Health Care Philos 2002; 5: 53-63.

61 Metcalfe A: Consultation on testing in minors recommendations, personal communication, 2008

62 Harper P, Clarke A: Genetics, Society and Clinical Practice. Oxford: Bios, 1997.

63 Codori AM, Zawacki KL, Petersen GM et al: Genetic testing for hereditary colorectal cancer in children: long-term psychological effects. Am J Med Genet A 2003; 116A: 117-128.

64 Allan D: Ethical boundaries in genetic testing. CMAJ 1996; 154: $241-244$.

65 Godard B, Kaariainen H, Kristofferson U et al: Provision of Genetic Services in Europe - current practices and issues. Eur J Hum Genet 2003; 11(Suppl 2): S13-S48.

66 European Society of Human Genetics: Provision of Genetic services in Europe - current practices and issues. Eur J Hum Genet 2003; 11(Suppl 2): S2-S4.

67 Clarke A: The Genetic Testing of Children. Oxford: Bios, 1998.

68 Clarke A, Flinter F: The genetic testing of children: a clinical perspective, in: Marteau $\mathrm{T}$, Richards $\mathrm{M}$ (eds): The Troubled Helix: Social and Psychological Implications of the New Human Genetics. Cambridge: Cambridge University Press, 1996, pp 164-176.

69 Clarke A: The genetic testing of children. J Med Genet 1995; 32: 492.

70 German Society of Human Genetics: Statement on genetic diagnosis in children and adolescents, http:/www.gfhev.de/en/gfh/, 1995.

71 Danish Council of Ethics: Genetic Investigation of Healthy Subjects - Report on Presymptomatic Gene Diagnosis. http:// www.etiskraad.dk/sw293.asp, 2001.

72 Borry P, Goffin T, Nys H, Dierickx K: Predictive genetic testing in minors for adult-onset genetic diseases. Mt Sinai J Med 2008; 75 : 287-296.

73 Rhodes R: Why test children for adult-onset genetic diseases? Mt Sinai J Med 2006; 73: 609-616.

74 Hayes CV: Genetic testing for Huntington's disease-a family issue. N Engl J Med 1992; 327: 1449-1451.

75 Grosfeld FJ, Beemer FA, Lips CJ, Hendriks KS, ten Kroode HF: Parents' responses to disclosure of genetic test results of their children. Am J Med Genet 2000; 94: 316-323.

76 Quaid KA, Morris M: Reluctance to undergo predictive testing: the case of Huntington disease. Am J Med Genet 1993; 45: $41-45$.

77 Malpas PJ: Why tell asymptomatic children of the risk of an adult-onset disease in the family but not test them for it? J Med Ethics 2006; 32: 639-642.

78 Rhodes R: Why test children for adult-onset genetic diseases? Mt Sinai J Med 2006; 73: 609-616.

79 Skirton H: Telling the children; in: Clarke A (eds): The Genetic Testing of Children. Oxford: Bios, 1998, pp 103-111.

80 Campbell E, Ross LF: Parental attitudes and beliefs regarding the genetic testing of children. Community Genet 2005; 8: 94-102.

81 Hamann HA, Croyle RT, Venne VL, Baty BJ, Smith KR, Botkin JR: Attitudes toward the genetic testing of children among adults in a Utah-based kindred tested for a BRCA1 mutation. Am J Med Genet 2000; 92: 25-32.

82 Benkendorf JL, Reutenauer JE, Hughes CA et al: Patients' attitudes about autonomy and confidentiality in genetic testing for breastovarian cancer susceptibility. Am J Med Genet 1997; 73: 296-303.

83 Evers-Kiebooms G: Predictief testen van minderjarigen voor aandoeningen die later in het leven tot uiting komen: psychologische aspecten en multidisciplinaire aanpak. Tijdschrift voor geneeskunde 2006; 62: 463-471.

84 Swiss Academy of Medical Sciences: Genetic investigations in humans, http://www.samw.ch/, 1993. 
85 Human Genetics Society of Australasia: DNA presymptomatic and predictive testing for genetic disorders, http://www.hgsa. com.au/policy/dnaptgd.html, 2002.

86 The American Society of Human Genetics Board of Directors and The American College of Medical Genetics Board of Directors: Points to consider: ethical, legal, and psychological impications of genetic testing in children and adolescents. Am J Hum Genet 1995; 57: 1233-1241.

87 Task Force on Genetic Testing: Promoting safe and effective genetic testing in the United States, http://www.genome.gov/ 10001733, 1997.

88 Canadian College of Medical Geneticists: Genetic testing of children, http://ccmg.medical.org/, 2000.

89 Bioethics Committee Canadian Paediatric Society: Guidelines for genetic testing of healthy children. Paediatr Child Health 2003; 8: $42-45$.

90 Committee on Bioethics: Ethical issues with genetic testing in pediatrics. Pediatrics 2001; 107: 1451.

91 Dalby S: GIG response to the UK Clinical Genetics Society report 'The genetic testing of children'. J Med Genet 1995; 32: 490-491.

92 Clarke A: The genetic testing of children. Working Party of the Clinical Genetics Society (UK). J Med Genet 1994; 31: 785-797.
93 American Medical Association: Testing children for genetic status, http://www.ama-assn.org/, 1995.

94 Barnes C: Carrier testing in childhood: conflict or compromise. http:// www.medacad.org/eshg/abstracts/eshgplenary.htm, 2002.

95 McConkie-Rosell A, Spiridigliozzi GA, Rounds K et al: Parental attitudes regarding carrier testing in children at risk for fragile X syndrome. Am J Med Genet 1999; 82: 206-211.

96 James CA, Holtzman NA, Hadley DW: Perceptions of reproductive risk and carrier testing among adolescent sisters of males with chronic granulomatous disease. Am J Med Genet 2003; 119C: 60-69.

97 Green NS, Dolan SM, Murray TH: Newborn screening: complexities in universal genetic testing. Am J Public Health 2006; 96: $1955-1959$

98 UK Newborn Screening Programme Centre: Newborn blood spot screening in the UK Policies and Standards. http://www. newbornbloodspot.screening.nhs.uk/download/policies_standards.pdf, 2005.

99 Health Resources and Services Administration: Newborn Screening: Toward a Uniform Screening Panel and System, $\mathrm{ftp}: / / \mathrm{ftp}$.hrsa.gov/mchb/genetics/screeningdraftforcomment.pdf, 2005. 